\title{
NIKETCHE: UMA HISTÓRIA DE POLIGAMIA EM LEITURA SOB A PERSPECTIVA DOS ESTUDOS CULTURAIS
}

Carina de Lima Carvalho'

DOI 10.11606/issn.1981-7169.crioula.2017.126067

RESUMO: Este artigo propõe reflexões acerca do romance Niketche: uma história de poligamia, de Paulina Chiziane, particularmente abordando a temática da poligamia em relação aos estudos culturais. Para isso, acolhemos as discussões levantadas por Jonathan Culler em seu trabalho sobre esse campo de estudo e a literatura.

ABSTRACT: This paper proposes considerations about the novel Niketche: a story of polygamy, by Paulina Chiziane, particularly approaching the theme of polygamy in relation to cultural studies. For this purpose, we accept the discussions raised by Jonathan Culler in his work on this field of study and literature.

PALAVRAS-CHAVE: Estudos culturais; Estudos literários; Literatura moçambicana; Paulina Chiziane; Poligamia.

KEYWORDS: Cultural studies; Literary studies; Mozambican literature; Paulina Chiziane; Polygamy.

1 Mestranda do Programa de Pós-Graduação em Letras da Universidade Federal de São Paulo (UNIFESP), desenvolvendo pesquisa sobre a poeticidade em Niketche: uma história de poligamia, de Paulina Chiziane. 
REVISTA CRIOULA N ${ }^{\circ} 19-1^{\circ}$ SEMESTRE/2017

\section{INTRODUÇÃO}

2. e no estudo da literatura produzida em nosso país há - que se observar a vasta gama de particularidades culturais que podem sobressair em cada obra, quando tratamos das literaturas estrangeiras, parece abrir-se diante de nós um leque analítico e interpretativo ainda maior. Surgem problemáticas que, para além de promissoras, inicialmente intrigam: com que ferramentas operar esse campo que não nos "pertence" por origem, mas se abre a nós como convite para um reconhecimento? Quanto de nosso olhar não estaria condicionado a uma base de saber hegemônica, que não se ajusta exatamente a conceitos e práticas próprios de algum país do outro lado do planeta? Como criar essa aproximação?

Por transpor parte da barreira linguística à leitura, a literatura produzida pelos países africanos de língua portuguesa chega como terreno fértil para a análise associada aos estudos culturais. São vários os enfoques possíveis no caso de Niketche: uma história de poligamia, de Paulina Chiziane, obra que tem Moçambique como pano de fundo e, mais do que isso, tema expandido do enredo. O surgimento de uma identidade nacional, os vestígios da colonização, a prática do lobolo² ou dos ritos de iniciação, a realidade pós-guerra e o papel social da mulher são exemplos de eixos que sustentam a história e fornecem muitas matérias enquanto caminho de pesquisa. Abordando aqui a poligamia, contudo, acabam presentes porções de todos esses tópicos, uma vez que ela se mostra, na

2 O lobolo é uma prática ainda existente em algumas regiões de Moçambique, em que a família do noivo oferece à família da noiva uma espécie de dote, em dinheiro e muitas vezes em cabeças de gado, quando ocorre um casamento. 
obra, como tema de debate tanto em relação ao mecanismo que a sustenta por dentro quanto àquilo que expõe, reverbera e atinge os aspectos sociais mais externos.

Os estudos culturais se configuram, de maneira geral, como um campo do conhecimento que estuda os aspectos culturais e se articula, interdisciplinarmente, a diferentes áreas do saber, como a sociologia, história, filosofia e literatura área esta foco deste trabalho. Assim, procuraremos propor reflexões acerca da poligamia em Niketche, aspecto cultural que, de pronto, se destaca quando tratamos de tal obra, com base nas perspectivas de Jonathan Culler sobre a relação entre a literatura e os estudos culturais.

A análise não tem a intenção de endurecer a leitura ficcional, no sentido de propor que sua interpretação ocorra sempre pelo viés investigativo das identidades culturais ali presentes, mas incentivar esse olhar como possibilidade. Assim, assumimos que uma leitura não se mostra menos profícua quando desconhece antecipadamente traços peculiares do contexto sociocultural em que o livro foi produzido ou que procura reproduzir - sua assimilação pode acontecer, ao contrário, a partir da própria obra, de dentro para fora.

\section{Chiziane, Moçambique e suas margens}

A fim de abrir caminho para as reflexões sobre a poligamia no romance, aspecto-chave de nossa análise, situamos agora, brevemente, a abordagem da temática e a autora no universo da literatura moçambicana. Segundo Fonseca e Moreira, considerável parte "da produção literária moçambicana 
deve-se a escritores que centram a sua temática nos problemas de Moçambique. Foram eles que contribuíram decisivamente para a formação da identidade nacional moçambicana" (2007, p. 42). O país aparece, desta forma, não somente como palco para o que pretendem manifestar os escritores que se propõem a testemunhar seu tempo, mas como forte tema das produções, em suas carências, anseios e protestos.

Embora ainda bastante recente, pelos marcos da colonização e independência, a literatura de Moçambique esboça algumas fases cujas características permitem divisão. Em um panorama realizado por Fonseca e Moreira (2007) sobre as literaturas africanas de língua portuguesa, há o estabelecimento de três fases nesse processo de construção: a fase colonial, a fase nacional e a fase pós-colonial. Em seu conjunto, são ressaltados: problemas resultantes do domínio colonial, que refletem na situação dos negros e mestiços; racismo, exploração e segregação; revolta contra os resquícios coloniais e esperança na construção de uma sociedade transformada; busca, na escrita, por estabelecer uma comunicação de cunho político, de combate; nacionalidade; e, enfim, na literatura mais recente, um tom de certa forma intimista, que testemunha a experiência pós-colonial de seus autores. Constatamos em diversas facetas uma força que, além de representativa em aspectos culturais, reflete processos históricos pelos quais passou o país e cujos frutos ainda hoje são colhidos.

A temática que permeia grande parte dos poemas, contos e romances acaba ainda por acrescentar indícios de que uma identidade nacional se forma por meio de experiências históricas e culturais de autor e público leitor. Tão marcada, a 
recorrência do país na literatura indica que esta é uma matéria bastante presente na pele de quem ali vive, de modo que acaba impossível desvinculá-la das produções artísticas - desligamento que, aliás, não nos parece interessante. A escritora Paulina Chiziane, em entrevistas, costuma dizer que Moçambique é um país ainda por ser escrito ${ }^{3}$.

A existência de um texto literário pressupõe um autor, um contexto em que ele se insere e uma determinada situação sociocultural. O social vive no texto enquanto os aspectos culturais reverberam e, ainda que possa haver uma intenção autoral de realizar obra "isenta" deles no que toca ao enredo, em algum ponto de análise tais fatos se impõem como questão. $\mathrm{O}$ ato da escrita já indica, em si, a possibilidade que uma pessoa tem de fazê-lo, de desenvolver essa atividade - exemplo simples que, se não justifica os estudos culturais a partir do texto, direciona o olhar para questões potenciais naquilo que o cerca e estrutura.

A cultura popular se mostra, segundo o percurso feito por Culler, quando esclarece a genealogia dos estudos culturais, com a finalidade de trazer à tona aspectos renegados da vida cotidiana, do que ocorre fora do circuito intelectual e canônico. Nessa produção, recebem luz práticas culturais inerentes a grupos marginalizados, não participantes de um círculo de prestígio social.

Particularmente importante, portanto, é o estudo das culturas e identidades culturais instáveis que se colocam para grupos - minorias étnicas, imigrantes e mulheres - que podem ter proble-

3 CHIZIANE, P. Não volto a escrever. Basta! (entrevista). Disponível em: <http://opais. sapo.mz/index.php/entrevistas/76-entrevistas/41298-nao-volto-a-escrever-basta. html>. Acesso em: 20 abr. 2017. 
mas em identificar-se com a cultura mais ampla na qual se encontram - uma cultura que é ela própria uma construção ideológica que sofre mudanças. (CULLER, 1999, p. 52).

Apoiando a análise nessa relação centro versus periferia (compreendida aqui como espaço das minorias) estabelecida por Culler, compreendemos que a literatura de Paulina Chiziane acaba por não identificar-se com o espectro maior em que está inserida. Isso porque a abordagem de temas como a poligamia em um romance, de um ponto de vista feminino, desponta no país em meio à produção majoritariamente masculina da época. Além disso, permite focos de estudo específicos, que não supervalorizem ou menosprezem tal voz em comparação com a de outras produções, mas que permitam identificar sua contribuição para os estudos literários e aprofundar a compreensão de outros critérios de valor. A leitura de Niketche: uma história de poligamia pelo viés dos estudos culturais amplia o leque interpretativo do romance e permite considerarmos o estudo, assim, um "fenômeno intertextual complexo" (CULLER, 1999, p. 53) diante de determinadas experiências que não vivenciamos, por exemplo, no Brasil. A descentralização proporcionada por essa literatura, como destaca a professora Tania Macedo, ocorre ainda em relação ao espaço geográfico:

Na prosa de Paulina Chiziane encontramos todo um universo do interior de Moçambique, constituindo um mergulho em costumes, lendas e perspectivas de populações distantes do litoral e, portanto, com um maior afastamento da cultura 
ocidental, que predomina em cidades como a capital, Maputo. (MACEDO, 2010).

Ainda sobre a imersão cultural que nos proporcionam os romances, citamos a oralidade característica das literaturas africanas em língua portuguesa, que também - e principalmente - em Paulina se faz presente. Do que se escuta pelas ruas, do que acontece nas casas vizinhas e de diálogos próprios e alheios é composta a matéria-prima dos enredos em que a cultura popular emerge. Não à toa, a escritora se autointitula contadora de histórias, rejeitando com veemência a alcunha de romancista, ainda que pelo formato romanesco encontre seu meio de expressão.

\section{Nos passos de Niketche}

Procuramos, aqui, feito esse panorama, não tratar a poligamia como mero aspecto da cultura moçambicana, desprovido de substância no âmbito dos estudos literários, tampouco ignorar o teor de representação e denúncia que nela pode residir quando participante de uma manifestação artística. Enquanto destaque do livro, presente aliás em seu título, a poligamia se revela como terreno farto às análises. $O$ ponto de vista feminino acontece por muitos ângulos possíveis, seja considerando o gênero da autora - que declaradamente se coloca como porta-voz das outras mulheres -, seja em relação à protagonista, que, segundo suas vivências, descreve sentimentos e reflexões sobre a prática poligâmica instaurada. É de dentro dessa cultura, portanto, que a produção de Chiziane a critica; mais do que isso, é a partir de técnicas lite- 
rárias que nos toca a problemática da figura feminina, naquele cenário, marginalizada.

Metaforicamente, já no título da obra, topamos com a dança do amor que abarca grande número de participantes, não restritos aos protagonistas da relação, Rami e Tony:

Niketche, a dança do sol e da lua, dança do vento e da chuva, dança da criação. Uma dança que mexe, que aquece. Que imobiliza o corpo e faz a alma voar. As raparigas aparecem de tangas e missangas. Movem o corpo com arte saudando o despertar de todas as primaveras. Ao primeiro toque do tambor, cada um sorri, celebrando o mistério da vida ao sabor do niketche. Os velhos recordam o amor que passou, a paixão que se viveu e se perdeu. As mulheres desamadas reencontram no espaço o príncipe encantado com quem cavalgam de mãos dadas no dorso da lua. Nos jovens, desperta a urgência de amar, porque o niketche é sensualidade perfeita, rainha de toda a sensualidade. Quando a dança termina, podem ouvir-se entre os assistentes suspiros de quem desperta de um sonho bom. (CHIZIANE, 2004, p. 160).

Niketche é uma dança das províncias Zambézia e Nampula, região norte de Moçambique, executada em rituais de iniciação sexual feminina. Rami, da região sul do país, ao investigar a vida de seu marido, pela desconfiança de que teria uma amante, descobre que, na verdade, suas "concorrentes" são quatro mulheres. À caça delas, os atritos são criados na medida em que cada uma, à sua maneira, empreende forças 
na luta pelo amor. Empenhada em reconquistar o próprio marido, Rami matricula-se para aulas de amor e sedução, em que aprende simpatias várias, que vão dos rituais de iniciação praticados em algumas províncias aos truques que evocam a sensualidade e o erotismo, a ponto de sentir-se ingênua nas artes do amor. É também no multifacetado bojo de características femininas que se manifesta a expressão cultural na obra. Oriundas de várias partes do país,

[...] tais mulheres são a representação da face cultural poliédrica de Moçambique. Elas metonimizam o encontro das culturas do norte, do sul e do centro do país. [...] Assim, se a terra é um múltiplo cultural, também é necessário propor uma múltipla figuração das imagens femininas para com ela reforçar o peso da diversidade. (PADILHA, 2013, p. 173).

O olhar de Rami, a protagonista, não se limita ao julgamento quanto à posição do homem no sistema poligâmico de que participa e em que observa as demais mulheres, mas se estende à própria consciência de si e às vidas e espaços ocupados pelas outras integrantes do movimento amoroso. Essa voz surgida sobre um sistema que beneficia o homem, tratando dele não de uma posição superior ou externa, mas central, subverte a ordem de que a poligamia permaneça como tabu, principalmente na boca de seu lado menos favorecido. Tal tabu se evidencia quando, por exemplo, percebemos que a prática poligâmica ocorre de forma velada. Em determinado capítulo do romance, há uma festa organizada pela matriarca Rami em que está presente, completa, toda a família de seu 
marido - esposas e mais de uma dezena de filhos. Nessa ocasião, o homem sente-se constrangido após perceber que os outros participantes da festa, mesmo polígamos mais veIhos, julgam a situação exagerada; as relações existem e continuam, são até mesmo motivo de orgulho em determinadas conversas masculinas, mas sob os olhos da sociedade, cabe o ocultamento. Nesse sentido, transportando o romance para o dia a dia em Moçambique, notamos que a ficção remete sempre à tradição e a aspectos culturais reais para construir os meandros do enredo.

Porque poligamia é poder, porque é bom ser patriarca e dominar. Conheço um povo com tradição poligâmica: o meu, do sul do meu país. Inspirado no papa, nos padres e nos santos, disse não à poligamia. Cristianizou-se. Jurou deixar os costumes bárbaros de casar com muitas mulheres para tornar-se monógamo ou celibatário. Tinha o poder e renunciou. A prática mostrou que com uma só esposa não se faz um grande patriarca. Por isso os homens deste povo hoje reclamam o estatuto perdido e querem regressar às raízes. Praticam uma poligamia tipo ilegal, informal, sem cumprir os devidos mandamentos. Um dia dizem não aos costumes, sim ao cristianismo e à lei. No momento seguinte, dizem não onde disseram sim, ou sim onde disseram não. Contradizem-se, mas é fácil de entender. A poligamia dá privilégios. Ter mordomia é coisa boa: uma mulher para cozinhar, outra para lavar os pés, uma para passear, outra para passar a noite. Ter re- 
produtoras de mão-de-obra, para as pastagens e gado, para os campos de cereais, para tudo, sem o menor esforço, pelos simples facto de ter nascido homem. (CHIZIANE, 2004, p. 92).

A perspectiva feminina, em testemunho e desabafo, não considera que a perpetuação dessa prática tradicional Ihe seja benéfica; pelo contrário, esclarece a posição dominadora do homem em relação à mulher, subjugada na relação amorosa e no que deriva dela (o cuidado com o lar, com os filhos e até com a renda). A crítica se dá, explícita no trecho apresentado, quanto à adoção pelos homens ora da monogamia cristã, ora da tradição poligâmica, conforme a conveniência. Há, assim, uma queixa principalmente por certa posição de hipocrisia masculina e seus métodos de manutenção do poder.

Em Niketche, entendemos como contínuos os processos de subjugação, que ultrapassam um possível pensamento reducionista entre vilania (homens) e vitimização (mulheres). Isso porque, embora na cadeia de dominação estabelecida a figura feminina seja subordinada à masculina, o homem também ocupa uma posição de dominado em relação à cultura colonizadora (central). Ocorre que ele se utiliza do retorno à tradição e às memórias culturais para adotar uma prática que o beneficia e, mais ainda, marginaliza as mulheres. A figura masculina cumpre na narrativa um papel mais fluido, que oscila entre as "leis" do dominador e os costumes introjetados na história de seu povo. Por essa reprodução do domínio é que se justificaria a poligamia, destinando à mulher, por consequência, uma opressão dupla. 
O estudo das identidades culturais instáveis, nas palavras de Culler (1999, p. 52), ratifica sua importância na medida em que a poligamia na literatura de Chiziane vem no sentido de representar, sim, um aspecto cultural, porém sob problematização. A tradição ali não se afirma como melhor escolha ou prática que clame retomada. Uma cultura "de margem", socialmente representativa, não se afirma de modo automático quando o domínio do estrangeiro é negado; o atrito está posto em debate nessa faceta da cultura que, para a personagem, não oferece acolhimento sob nenhum ângulo. Chiziane provoca, dessa forma, a reflexão acerca de valores morais e éticos que perpassam o conceito de cultura e ressurgem na literatura para apontar uma voz feminina subjugada que já se coloca, mas cujo espaço permanece à margem.

A perspectiva dos estudos culturais aplicada à leitura de Niketche se mostra como um campo vasto para reflexão. $O$ artigo procurou contribuir no sentido de verificar alguns elementos que passam a se revelar na literatura tida como representativa de experiências culturais por vezes ainda encobertas. Tais experiências se revelam ricas principalmente no que tange às literaturas africanas em língua portuguesa. A poligamia no romance de Paulina Chiziane chega enquanto forte símbolo de atrito nos eixos margem versus centro (literário e social) e como enunciadora da identidade feminina, mas suas possibilidades não se encerram aí. Embora o assunto suscite, ainda, uma série de questões cujas respostas talvez só cheguem em algum tempo, ficam estabelecidos pressupostos que oferecem vislumbre do lugar ocupado atualmente pela voz feminina nessa literatura. 


\section{REFERÊNCIAS BIBLIOGRÁFICAS}

CHIZIANE, Paulina. Niketche: uma história de poligamia. São Paulo: Companhia das Letras, 2004.

CULLER, Jonathan. Literatura e estudos culturais. In: Teoria literária: uma introdução. São Paulo: Beca Produções Culturais Ltda., 1999. p. 48-58.

FONSECA, Maria Nazareth Soares; MOREIRA, Terezinha Taborda. Panorama das literaturas africanas de língua portuguesa. In: Literaturas africanas de língua portuguesa - Cadernos Cespuc de Pesquisa - Série Ensaios, Belo Horizonte: Editora PUC Minas, 16:13-69, 2007.

MACEDO, Tania. Da voz quase silenciada à consciência da subalternidade: a literatura de autoria feminina em países africanos de língua oficial portuguesa. Mulemba - UFRJ, Rio de Janeiro, jun. 2010. Disponível em: <https://revistas.ufrj.br/index.php/mulemba/article/view/4682/3441>. Acesso em: 20 abr. 2017.

PADILHA, Laura Cavalcante. Capulanas e vestidos de noiva: leitura de romances de Paulina Chiziane. In: SECCO, Carmen Lucia Tindó Ribeiro; MIRANDA, Maria Geralda de (Orgs.). Paulina Chiziane: vozes e rostos femininos de Moçambique. Curitiba: Editora Appris, 2013. p. 161-176.

Submissão: 2017-02-05

Aceite: 2017-04-25 